\title{
Structural, morphological, optical and diode properties of chemical bath deposited nano-structured CdS thin films using EDTA as a complexing agent
}

\author{
S.N. VIDHYA ${ }^{1,2, *}$, R.T. KARUNAKARAN ${ }^{3}$ \\ ${ }^{1}$ Research and Development Centre, Bharathiar University, Coimbatore 641046, Tamilnadu, India \\ ${ }^{2}$ Department of Physics, PSGR Krishnammal College for Women, Coimbatore 641004, Tamilnadu, India \\ ${ }^{3}$ Department of Physics, Governtment Arts College, Udumalpet 642146, Tamilnadu, India
}

$\mathrm{CdS}$ thin films with $\left(\begin{array}{lll}1 & 1 & 1\end{array}\right)$ orientation were prepared by chemical bath deposition technique at $80 \pm 5^{\circ} \mathrm{C}$ using the reaction between $\mathrm{NH}_{4} \mathrm{OH}, \mathrm{CdCl}_{2}$ and $\mathrm{CS}\left(\mathrm{NH}_{2}\right)_{2}$. The influence of annealing temperature varying from $150{ }^{\circ} \mathrm{C}$ to $250{ }^{\circ} \mathrm{C}$ was studied. $\mathrm{X}$-ray diffraction studies revealed that the films are polycrystalline in nature with cubic structure. Various parameters, such as dislocation density, stress and strain, were also evaluated. SEM analysis indicated uniformly distributed nano-structured spherically shaped grains and net like morphology. Optical transmittance study showed the wide transmittance band and absence of absorption in the entire visible region. I-V characterization of $\mathrm{p}-\mathrm{Si} / \mathrm{n}-\mathrm{CdS}$ diode and photoluminescence studies were also carried out for the CdS films.

Keywords: thin films; chemical bath; structural properties; optical properties

\section{Introduction}

For the past two decades a huge number of investigations have been carried in order to produce $\mathrm{CdS}$ thin films with suitable properties for various semiconductors. Due to their low cost and high efficiency, recently, much alternation has been focused on cadmium sulfide as an alternative material for photovoltaic application. Chemical bath deposited CdS films are commonly used for the buffer layer or window material for inorganic solar cells (CdTe, CIGS, etc.). To date, small area CdS/CdTe solar cells (glass/(TCO)/CdS/CdTe/back contact (metal)) with efficiency of $19.72 \%$ have been reported [1-4]. Other applications include optoelectronic materials, such as photodetectors, optical filters, photodiodes, phototransistors, piezoelectric transducers and light emitting diodes. Due to its desirable properties, such as direct optical band gap $(2.2 \mathrm{eV})$ and high absorption coefficient, cadmium chalcogenide belongs to an essential class of materials [5-8]. CdS thin films have already been

*E-mail: vidhyadamayanthi@gmail.com prepared by a number of methods which included thermal evaporation, spray pyrolysis, anodic oxidation, electrodeposition, sputtering and chemical bath deposition $[9,10]$. Among these techniques, chemical bath deposition is a well-known, simplest and cheapest aqueous technique for depositing large area thin films. CBD is controllable by solution $\mathrm{pH}$ and temperature which can facilitate better orientation of the crystallites with improved grain size. In order to improve the quality of the CdS films a large number of investigations were made. Kumar et al. [11] studied physical and optical properties of $\mathrm{CdS}$ thin films with different EDTA concentration and they found that $0.006 \mathrm{M}$ is the best one. Based on these facts, in the present investigation, CdS thin films were grown by chemical bath deposition technique at $80 \pm 5^{\circ} \mathrm{C}$ by using EDTA as a chelating agent $(0.006 \mathrm{M})$. After deposition, the films were annealed at various temperatures $\left(150{ }^{\circ} \mathrm{C}, 200{ }^{\circ} \mathrm{C}\right.$ and $\left.250{ }^{\circ} \mathrm{C}\right)$. The annealed films were characterized by X-ray diffraction studies, scanning electron microscope (SEM) and optical studies. 


\section{Experimental}

Chemical bath deposition technique was adopted for the preparation of cadmium sulfide thin films. The chemicals used for the preparation: cadmium chloride (99\%) and thiourea (99\%) were of analytical grade. The deposition of $\mathrm{CdS}$ thin films was based on the reaction of cadmium chloride and thiourea in deionized water solution. Chemical baths used for the deposition of $\mathrm{CdS}$ thin films consisted of cadmium chloride, thiourea and ammonia. The $\mathrm{pH}$ of the solution was adjusted by adding ammonia. Thin film deposition was carried out at the temperature of $80 \pm 5{ }^{\circ} \mathrm{C}$. Two different molar proportions of cadmium chloride and thiourea, namely 0.1:0.9 and 0.2:08 were employed, and $0.006 \mathrm{M}$ of EDTA was added into the final solution. The deposition process was performed at various $\mathrm{pH}$ values of the bath from 0 to 10 . The $\mathrm{pH}$ of solution was measured using digital $\mathrm{pH}$ meter. The cleaned glass substrates were vertically immersed into the bath solution. The bath was maintained under constant stirring during deposition. After the deposition, the CdS films were washed ultrasonically to remove the loosely adhered $\mathrm{CdS}$ particles from the film and finally dried in air.

\section{Results and discussion}

\subsection{Structural properties}

The deposited films were annealed in air at $150{ }^{\circ} \mathrm{C}, 200{ }^{\circ} \mathrm{C}$ and $250{ }^{\circ} \mathrm{C}$ for $1 \mathrm{~h}$ and then they were subjected to the X-ray diffraction analysis. The results of the analysis were recorded by the Philips Model PW1710 diffractometer with $\mathrm{CuK} \alpha$ radiation $(\lambda=0.1542 \mathrm{~nm})$. The structure of the CBD-CdS films annealed at different temperatures is shown in Fig. 1. The sharp intense peaks at $2 \theta=26.82^{\circ}, 29.61^{\circ}$ and $51.51^{\circ}$ correspond to ( $\left(\begin{array}{lll}1 & 1 & 1\end{array}\right),\left(\begin{array}{lll}2 & 0 & 0\end{array}\right)$ and ( $\left.\begin{array}{lll}3 & 1 & 1\end{array}\right)$ planes of CdS with cubic crystal phase. All the samples are polycrystalline in nature with cubic structure and they are in good agreement with the standard JCPDS Card No. 89-0440 [7]. The presence of the (llll) peak in the XRD pattern confirms the formation of CdS. Its lattice constant value was found to be 5.8734 .
The intensity of the diffraction peaks increases obviously as the annealing temperature increases. Thus, the annealing process can improve the crystallinity of the CdS films. Moreover, the full width at half maximum (FWHM) of the films decreases as the annealing temperature increases, and it indicates that the grains grew after annealing $[12,13]$. Crystallite size was estimated from the FWHM of the diffraction peaks using Scherer equation:

$$
D=k \lambda / \beta \cos \theta
$$

where the constant $\mathrm{k}$ is the shape factor $=0.94, \lambda$ is the wavelength of $\mathrm{X}$-ray $(1.5406 \AA$ for $\mathrm{CuK} \alpha), \theta$ is the Bragg angle and $\beta$ is the FWHM. The dislocation density $\delta$ can be evaluated from Williamson and Smallman formula:

$$
\delta=1 / D^{2} \text { lines } / \mathrm{m}^{2}
$$

The microstrain $\epsilon$ can be obtained using the relation:

$$
\varepsilon=\beta \cos \theta / 4
$$

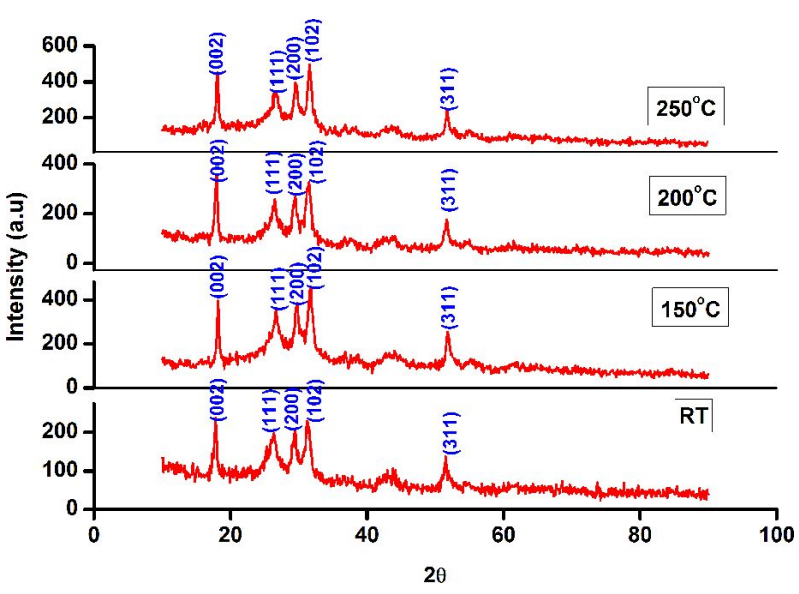

Fig. 1. XRD patterns of CdS thin films.

The calculated grain size $\mathrm{D}$, dislocation density $\delta$ and microstrain $\epsilon$ were estimated and presented in Table 1. The XRD data show that the peak intensity increases with temperature which is due to improvement in the crystallinity and decreasing internal microstrain of the film. 
Table 1. Structural parameters of CdS thin films.

\begin{tabular}{|c|c|c|c|c|c|c|c|}
\hline $\begin{array}{l}\text { Temp } \\
{\left[{ }^{\circ} \mathrm{C}\right]}\end{array}$ & $\begin{array}{c}2 \theta \\
{[\mathrm{rad}]}\end{array}$ & $\begin{array}{c}\text { d-spacing } \\
{[3 \mu \mathrm{m}]}\end{array}$ & FWHM & h k l & $\begin{array}{c}\mathrm{D} \\
{[\mathrm{nm}]}\end{array}$ & $\begin{array}{c}\delta \mathrm{x} \\
{\left[10^{14} \text { lines per } \mathrm{m}^{2}\right)}\end{array}$ & $\begin{array}{c}\epsilon \mathrm{X} \\
{\left[10^{4} \text { lines }^{-2} \text { per }^{-4}\right]}\end{array}$ \\
\hline 80 & 26.28 & 3.391 & 0.787 & 111 & 10.83 & 8.01 & 3.34 \\
\hline 150 & 26.67 & 3.341 & 0.590 & 111 & 14.45 & 6.82 & 2.50 \\
\hline 200 & 26.39 & 3.376 & 0.492 & 111 & 17.45 & 4.49 & 2.07 \\
\hline 250 & 26.75 & 3.332 & 0.393 & 111 & 19.22 & 2.96 & 1.88 \\
\hline
\end{tabular}

\subsection{Morphological properties}

To study the homogeneity of the films and to compare one with another, the as-prepared and annealed $\mathrm{CdS}$ thin films were subjected to SEM analysis (Philips Model XL 30). Fig. 2 illustrates the SEM micrographs of the surfaces of the asprepared and annealed samples. These images reveal that an increase in the annealing temperature affects the surface morphology of the $\mathrm{CdS}$ films markedly. Initially, the crystalline grains of CdS films are very small and non-uniform (monodispersed), with the presence of large intercrystalline spacing for the films annealed at low temperature. The intercrystalline spacing reduced when the annealing temperature increased. For higher temperatures a clear improvement in crystalline structure of the films is observed which agrees with Scherer results. The increase in temperature causes a significant increase in the size of the agglomerates in the thin film. Further, the morphology of the grains is observed to be near spherical and is more uniform throughout the analyzed area of the specimen $[6,14]$. However, it is noteworthy that the $\mathrm{CdS}$ film annealed at $250{ }^{\circ} \mathrm{C}$ displays a flake-netted structures with interconnections to each other. At low temperature, owing to the low rate of chemical reaction and ion diffusion to the grains, the surface grains grow too slow to combine with each other to create a continuous film which results in the existence of voids and smaller grain sizes compared to the films annealed at higher temperature of $250{ }^{\circ} \mathrm{C}$.

\subsection{Optical properties}

Optical transmittance spectra of chemical bath deposited $\mathrm{CdS}$ thin films were recorded in a function of wavelength in the range of $300 \mathrm{~nm}$ to $1100 \mathrm{~nm}$ by using a PerkinElmer Lambda 35 spectrometer. The recorded spectra are shown in Fig. 3a. All the spectra were recorded at room temperature. Transmittance studies show that the film transmittance increases with increase in the annealing temperature and all the films are transparent in the visible region. The optical absorption coefficient was calculated from the transmittance values by using the following relation:

$$
\alpha=\frac{2.3036 \log (1 / T)}{t}
$$

where $\mathrm{T}$ is the measured optical transmittance and $t$ is the thickness of the sample. According to Tauc relation the value of $\alpha$ has been used to determine the optical band gap. For high photon energies hv the absorption coefficient $\alpha$ obeys the following relation:

$$
\alpha=\frac{A\left(h v-E_{g)^{1 / 2}}\right.}{h v}
$$

where $E_{g}$ is the optical band gap of the crystal and $\mathrm{A}$ is a proportional constant, $\mathrm{h}$ is the Planck constant and $n$ is the frequency of the incident photons. In mono and polycrystalline materials optical transitions are possible depending on the material band structure. The type of transition responsible for absorption depends on the value of $n$, an index that can take any of the values $1 / 2,3 / 2,2$ or 3 for direct allowed, direct forbidden, indirect allowed or indirect forbidden transitions respectively. In the present case, $n=1 / 2$ means that the transition is an allowed direct transition. The optical band gap was estimated by extrapolating the linear portion of the plot $(\alpha \mathrm{h} v)^{2}$ vs. hv. The optical band gaps of CdS thin films deposited at bath temperature $80 \pm 5^{\circ} \mathrm{C}$, 


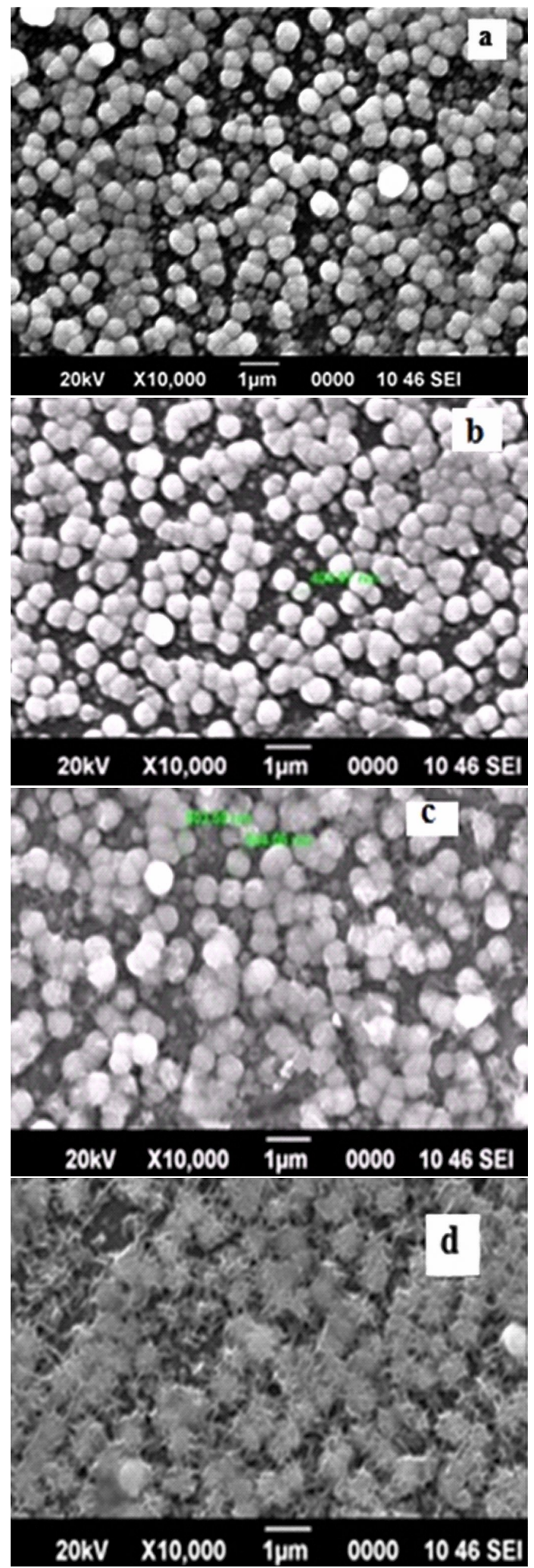

Fig. 2. Surface micrographs of CdS thin films: (a) asdeposited and annealed at (b) $150{ }^{\circ} \mathrm{C},(\mathrm{c}) 200^{\circ} \mathrm{C}$ and (d) $250{ }^{\circ} \mathrm{C}$. after annealing at $150{ }^{\circ} \mathrm{C}, 200{ }^{\circ} \mathrm{C}$ and $250{ }^{\circ} \mathrm{C}$ are shown in Fig. 3b and Fig. 3c. From the figure it is found that optical band gap decreases with an increase in the annealing temperature. The calculated optical band gap is about $2.87 \mathrm{eV}$ to $2.37 \mathrm{eV}$.

\subsection{I-V characteristics of $\mathbf{p - S i / n - C d S}$}

The formation of the P-N junction diode results from the connection of p-type Si and n-type $\mathrm{CdS}$. The diode characteristics were studied at ambient temperature using Keithley 6517B electrometer. The I-V characteristics of the $\mathrm{p}-\mathrm{Si} / \mathrm{n}-\mathrm{CdS}$ diode at ambient temperature are shown in Fig. 4a. The semi logarithmic plot of the current density lnJ vs. voltage $\mathrm{V}$ is shown in Fig. 4b. The current was measured in the range of $+4 \mathrm{~V}$ to $-4 \mathrm{~V}$. The characteristics of $\mathrm{p}-\mathrm{Si} / \mathrm{n}-\mathrm{CdS}$ show good rectifying nature of the junction. The diffusion voltage of the heterojunction was found to be $1.6 \mathrm{~V}$; and beyond these voltage, the forward bias current increased as the applied voltage increased. But the saturation current at reverse bias was very low. An ideal P-N junction diode, has zero resistivity at the forward bias and infinite resistivity at the reverse bias. According to the thermionic emission theory (TE), the current through the diode can be calculated as follows:

$$
I=I_{0} \exp \left(\frac{q V}{n K T}-1\right)
$$

where $I_{0}$ is the saturation current, $q$ is the electron charge, $\mathrm{V}$ is the applied voltage, $\mathrm{n}$ is the ideality factor, $\mathrm{K}$ is the Boltzmann constant and $\mathrm{T}$ is the absolute temperature.

The ideality factor $\mathrm{n}$ and the saturation current $\mathrm{I}_{\mathrm{O}}$ of the diode were determined from the slope and the intercept of the semi-logarithmic forward bias $\mathrm{J}-\mathrm{V}$ plot for $\mathrm{V} \geqslant 3 \mathrm{kT} / \mathrm{q}$ using equation 1 and the ideality factor $\mathrm{n}$ and the barrier height $\Phi_{\mathrm{b}}$ can be calculated as follows $[7,8]$ :

$$
n=\frac{q}{k T} \frac{d V}{d(\ln I)}
$$

$$
\Phi_{b}=\frac{k T}{q} \ln \left(\frac{A A^{*} T^{2}}{I_{0}}\right)
$$




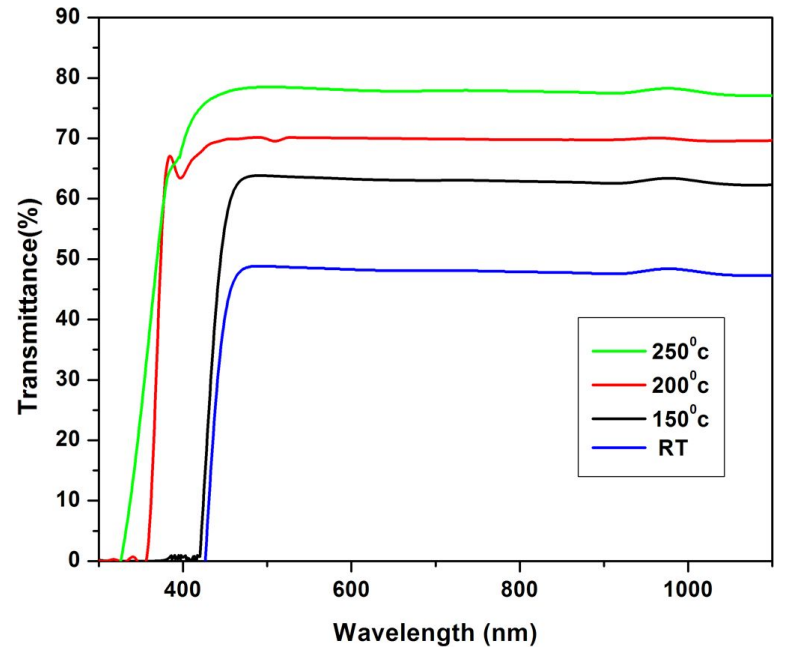

(a)

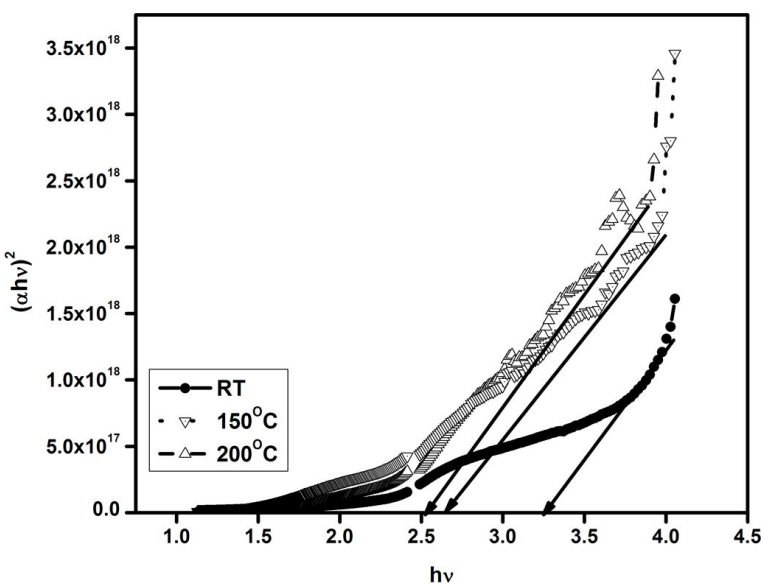

(b)

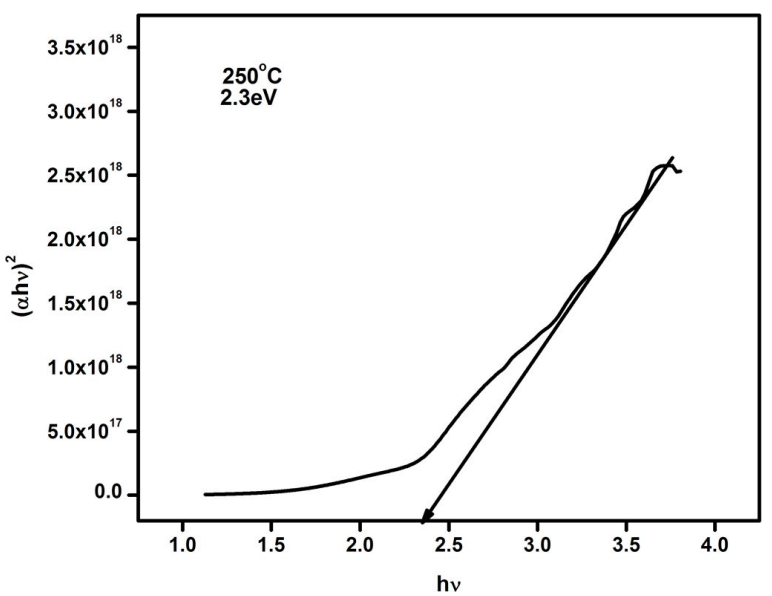

(c)

Fig. 3. (a) transmittance spectra of CdS thin films; (b) $(\alpha \mathrm{hv})^{2}$ vs. hv for CdS thin films not annealed (RT) and annealed at $150{ }^{\circ} \mathrm{C}$ and $200{ }^{\circ} \mathrm{C}$ ); (c) $(\alpha \mathrm{h} v)^{2}$ vs. hv for $\mathrm{CdS}$ thin films $\left(250^{\circ} \mathrm{C}\right)$.

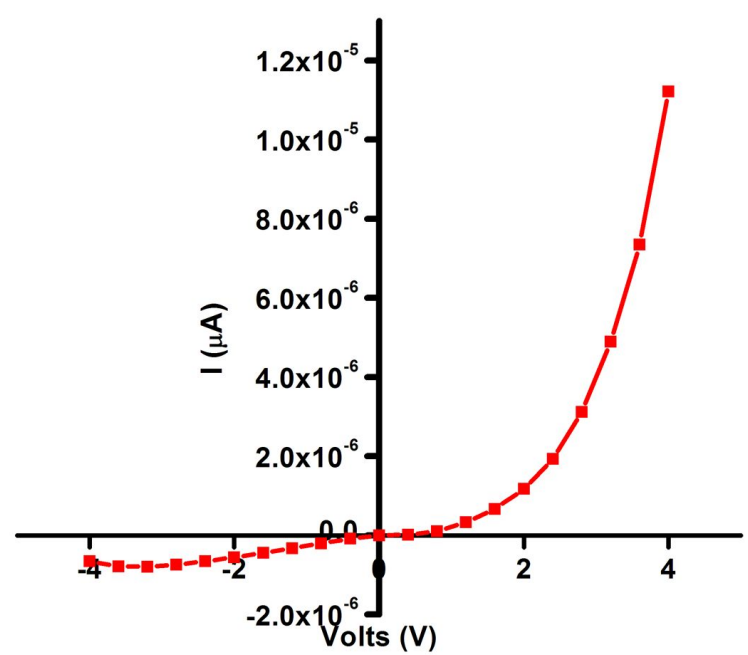

(a)

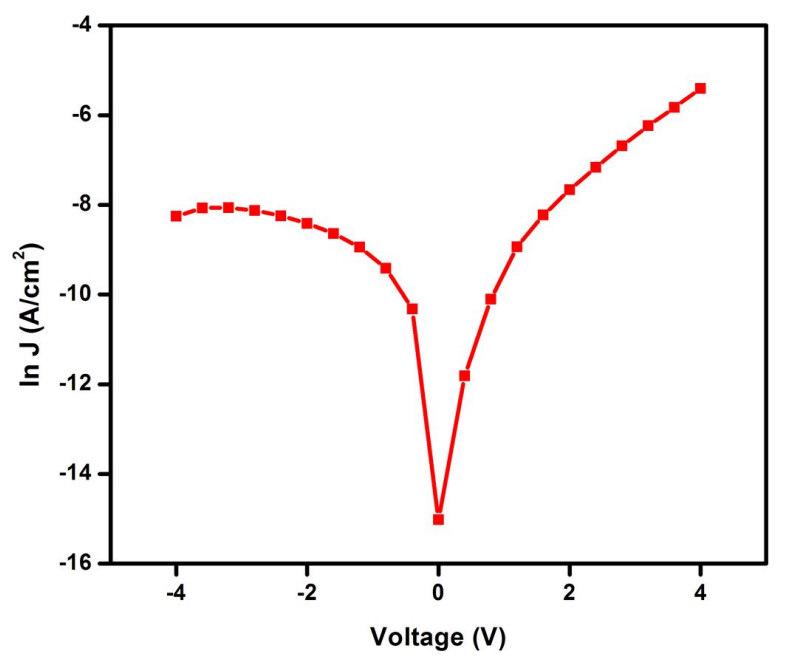

(b)

Fig. 4. (a) I-V characteristics of $\mathrm{p}-\mathrm{Si} / \mathrm{n}-\mathrm{CdS}$ diode at ambient temperature; (b) $\ln \mathrm{J}-\mathrm{V}$ characteristics of $\mathrm{p}-\mathrm{Si} / \mathrm{n}-\mathrm{CdS}$ diode at ambient temperature.

where $\mathrm{A}$ is the active area of the diode and $\mathrm{A}^{*}$ is the Richardson constant. For an ideal P-N diode, the ideality factor value is unity (i.e. $\mathrm{n}=1$ ) but experimentally, we obtained a higher value of ideality factor $\mathrm{n}=2.26$, for the $\mathrm{p}-\mathrm{Si} / \mathrm{n}-\mathrm{CdS}$ diode at ambient temperature which is higher than unity $(n>1)$. This is a non-ideal behavior, which may be due to the barrier inhomogeneity. It may also be due to series resistance and nonlinear metal-semiconductor contact. Another reason may be the inhomogeneity of the inorganic film thickness and non-uniformity 
of the interfacial charges. The variation of current in the $\mathrm{p}-\mathrm{Si} / \mathrm{n}-\mathrm{CdS}$ diode at ambient temperature is relevant to photodetection applications.

\subsection{Photoluminescence studies}

Photoluminescence spectra were recorded using Shimadzu RF5301 spectrofluorometer. Fig. 5 shows the photoluminescence (PL) emission spectra for the energies $3.16 \mathrm{eV}$ and $2.28 \mathrm{eV}$ respectively. Electrons and holes relax to their respective ground states in the conduction and valence band. They can then recombine radiatively as most free carriers under excitation. When light energy is applied to the film there occurs an electronic transition between two energy levels, $E_{1}$ and $E_{2}$ $\left(E_{2}>E_{1}\right)$, with the emission of wavelength $\lambda$, where:

$$
h c / \lambda=E_{2}-E_{1}
$$

$E_{1}$ and $E_{2}$ are a part of two groups of energy levels so that instead of a single emission wavelength a band of wavelength is observed [15]. The emission peak occurs at a higher wavelength than that of the absorption peaks. In fact, the peak emission wavelength is invariably shifted towards red end of the spectrum compared to the peak of the absorption spectrum. This phenomenon is known as the Stokes shift, which finds commercial application in the fluorescent lamps [16]. The PL spectra of CdS thin films show not only the well-known defect band but also the evidence for bound exciton recombination. These results show a good polycrystalline structure of our films. Similar results have been reported earlier for magnetron sputtered CdS thin films [17].

\section{Conclusions}

The CdS thin films were successfully obtained by the chemical bath deposition technique at $80 \pm 5{ }^{\circ} \mathrm{C}$ using EDTA as complexing agent. The films were annealed at $150{ }^{\circ} \mathrm{C}, 200{ }^{\circ} \mathrm{C}$ and $250{ }^{\circ} \mathrm{C}$ and then subjected to characterization studies. X-ray diffraction studies revealed that $\mathrm{CdS}$ films are polycrystalline in nature with cubic crystalline phase. Preferential orientation along (l $\left.\begin{array}{lll}1 & 1 & 1\end{array}\right)$ direction confirms the formation of $\mathrm{CdS}$.

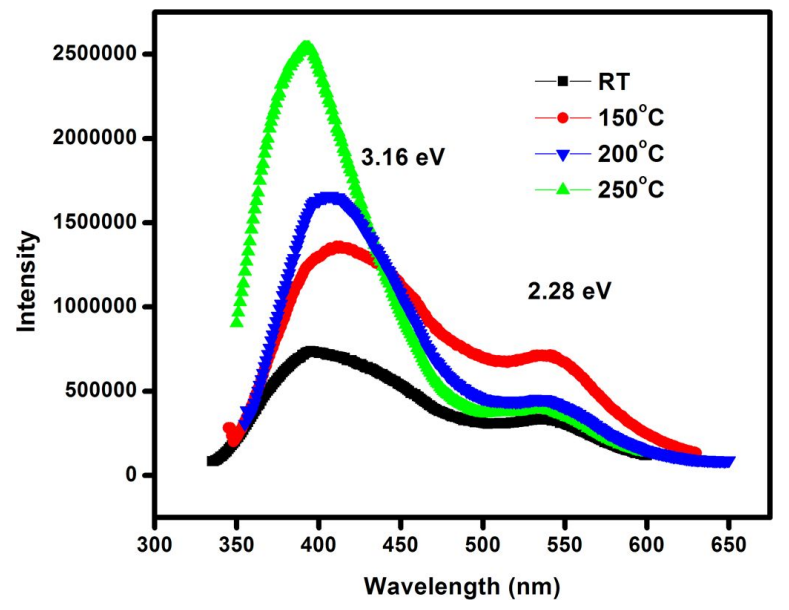

Fig. 5. Emission spectra of CdS thin films.

The increase in peak intensity and decrease in the internal microstrain of the film with temperature is due to the improvement in the crystallinity. Morphology of the grains is observed to be near spherical and improves with increasing temperature. The film annealed at $250{ }^{\circ} \mathrm{C}$ depicts a flake netted structures. The direct optical band gap was found to be $2.37 \mathrm{eV}$. I-V studies revealed the semiconductor nature of the $\mathrm{CdS}$ thin films. In conclusion, $\mathrm{CdS}$ have significant potential applications for the window layer in solar cells.

\section{References}

[1] Siddiquee K.A.M.H., Pathan M.A.K., Alama S., ISLAMA O., QADIR M.R., Optik, 124 (2013), 4383.

[2] Leonid Kosyachenko, Toshihiko Toyama, Sol. Energ. Mater. Sol. C., 120 (2014), 512.

[3] Kim M.J., LeE J.J., LeE S.H., Sohn S.H., Sol. Energ. Mater. Sol. C., 109 (2013), 209.

[4] Fardi H., Buny F., Int. J. Photoenergy, (2013).

[5] Kwon J.H., Ahn J.S., Yang H., Curr. Appl. Phys., 13 (2013), 84e89.

[6] Hani Khallaf, isaiah O. Oladeji, Guangyu Chai, LeE Chow, Thin Solid Films, 516 (2008), 7306.

[7] Mariappan R., Ponnuswamy V., RagavenDAR M., KRishnamoorthi D., SANKAR C., Optik, 123 (2012), 1098.

[8] Ashour A., Optoelectron. Adv. Mater-Rapid Commun., 8 (2006), 1447.

[9] Cao M., Sun Y., Wu J., Chen X., Dai N., J. Alloy. Compd., 508 (2010), 297.

[10] Mahdi M.A., Hassan Z., NG S.S., Hassan J.J., Mohd BAKHORI S.K., Thin Solid Films, 520 (2012), 3477. 
[11] Prem Kumar T., And Sankaranarayanan K., Can. J. Chem. Eng., 9999 (2012), 1.

[12] Prabahar S., Dhanam M., J. Cryst. Growth, 285 (2005), 41.

[13] Limei Zhou, Xiaofei Hu, Sumei Wu, Surf. Coat. Technol., 228 (2013), S171.

[14] FANGyANG LiU, YANQING Lai, JUn LiU, BowANG, Sanshuang KuAng, Zhian Zhang, Jie Li, YeXIANG LiU, J. Alloy. Compd., 493 (2010), 305.

[15] Kulp B.A., Kelley R.H., J. Appl. Phys., 31 (1960), 105.
[16] Wilson J., HaW Kes J.F.B., Optoelectronics-An Introduction, II Edition, Prentice Hall of India Publication, New Delhi 113 (1999).

[17] Hernandez-Contreras H., ContreasPuente G., Aguilar-Hernandez J., MoralesAcEVedo A., Vidal-Larramendi J., VigilGALAN O., Thin Solid Films, 403 (2002), 148.

Received 2016-09-18 Accepted 2019-04-23 